\title{
Simulation of agglomeration in spray dryers: the EDECAD project
}

\author{
Ruud E.M. VERDURMEN"*, Maykel VERSCHUEREN ${ }^{\mathrm{a}}$, Michiel GUNSING ${ }^{\mathrm{a}}$, \\ Han STRAATSMA ${ }^{\mathrm{a}}$, Stefan BLEI ${ }^{\mathrm{b}}$, Martin SOMMERFELD ${ }^{\mathrm{b}}$ \\ a NIZO food research, P.O. Box 20, 6710 BA, Ede, The Netherlands \\ b Martin Luther University Halle-Wittenberg, Department of Engineering Science, \\ Universitätsplatz 10, 06099 Halle (Saale), Germany
}

Published online 5 July 2005

\begin{abstract}
Spray drying is used for the manufacture of many consumer and industrial products such as instant dairy and food products, laundry detergents, pharmaceuticals, ceramics and agrochemicals. During spray drying, agglomerates of powder particles are formed, which determine the instant properties of the powder. Agglomeration during spray drying is considered to be a difficult process to control. The main cause of this is the complex interaction of the process variables: the atomization process, the mixing of spray and hot air, the drying of suspension droplets and the collision of particles which might lead to coalescence or agglomeration. As a consequence, agglomeration during spray drying is operated by trial-and-error. In an EC-sponsored project, named the EDECAD project and co-ordinated by NIZO food research, an industrially validated computer model, using Computational Fluid Dynamics (CFD) technology, to predict agglomeration processes in spray drying machines is developed. An Euler-Lagrange approach with appropriate elementary models for drying, collision, coalescence and agglomeration of the dispersed phase is used. The main result of the EDECAD project is a so-called "Design Tool", which establishes relations between the configuration of the drying installation (geometry, nozzle selection), process conditions, product composition and final powder properties. The Design Tool is being validated on pilot-plant scale and industrial scale. It will provide a tool for improved design and optimisation of spray drying and agglomeration equipment, to improve the quality of products and to increase the productivity of such equipment. This paper introduces the approach of the project and some preliminary results.
\end{abstract}

spray drying / agglomeration / computational fluid dynamics / modeling

Résumé - Simulation de l'agglomération dans les équipements de séchage par atomisation : le projet EDECAD. Le séchage par atomisation est utilisé dans la fabrication de nombreux produits de consommation et de produits industriels, tels que les aliments en préparation instantanée et les poudres laitières, les détergents pour lessive, les produits pharmaceutiques, céramiques ou agrochimiques. Au cours du séchage, des agglomérats de particules de poudre sont formés, qui déterminent les propriétés d'instantanéisation de la poudre. L'agglomération pendant le séchage par atomisation est un processus difficile à maîtriser, principalement en raison de l'interaction complexe des variables opératoires comme le mode d'atomisation, le mélange du spray avec l'air chaud, le séchage des gouttelettes en suspension et la collision des particules pouvant conduire à la fusion ou à l'agglomération. En conséquence, l'agglomération au cours du séchage est opérée par approximations successives. Dans un projet appelé EDECAD, soutenu par l'union européenne et coordonné par le NIZO, un modèle informatique validé industriellement, utilisant la technologie CFD, a été développé pour prédire l'agglomération dans les équipements de séchage par atomisation. Une approche EulerLagrange avec des modèles élémentaires appropriés pour le séchage, la collision, la fusion et

\footnotetext{
* Corresponding author: ruud.verdurmen@nizo.nl
} 
l'agglomération de la phase dispersée est utilisée. Le principal résultat du projet EDECAD est la mise au point d'un outil appelé « Design Tool » qui établit des relations entre la configuration de l'installation de séchage (géométrie, sélection de buses), les conditions opératoires, la composition du produit et les propriétés finales de la poudre. Le Design Tool est en cours de validation à l'échelle pilote et à l'échelle industrielle. Il permettra d'améliorer la conception et l'optimisation des équipements de séchage par atomisation et d'agglomération, pour améliorer la qualité des produits et pour accroître la productivité de tels équipements. Cet article présente l'approche du projet et quelques résultats préliminaires.

\section{séchage par atomisation / agglomération / dynamique des fluides / modélisation}

\section{INTRODUCTION}

Spray drying is an essential unit operation for the manufacture of many products with specific powder properties. It is characterized by atomization of a solution or suspension into droplets, followed by subsequent drying of these droplets by evaporation of water or other solvents. Spray drying is used for the manufacture of many consumer and industrial products such as instant food products, laundry detergents, pharmaceuticals, ceramics and agrochemicals. The best known example of an instant food product is milk powder. Consumers desire a quick dissolution or dispersion of such powders in water or milk without the formation of lumps. But also manufacturers have their wishes. They require free flowing powders and absence of dust in such a way that it facilitates the handling of the powders. Both requirements are met by applying agglomeration of food powders $[8,16,19]$.

Agglomeration is a size enlargement process of powders, where small particles combine to form large relatively permanent masses, in which the original particles are still identifiable, see also Figure 1. In this way the characteristics of a single particle are maintained while the bulk powder properties are improved by the creation of the larger agglomerates.

In a spray dryer agglomeration can take place within the spray of an atomizer, between sprays of various atomizers and between sprays and dry material being introduced into the drying chamber (e.g. by fines return, see Fig. 2). The latter technique is often the most effective way to achieve and control agglomeration in spray dryers.

Agglomeration during spray drying is considered to be a difficult process to control. The main cause of this is the complex interaction of the process variables: the atomization process, the mixing of spray and hot air, the drying of suspension droplets and the collision of particles which might lead to coalescence or agglomeration. As a consequence, agglomeration during spray drying is operated by trial-and-error. In 2001 an EC-sponsored project started,

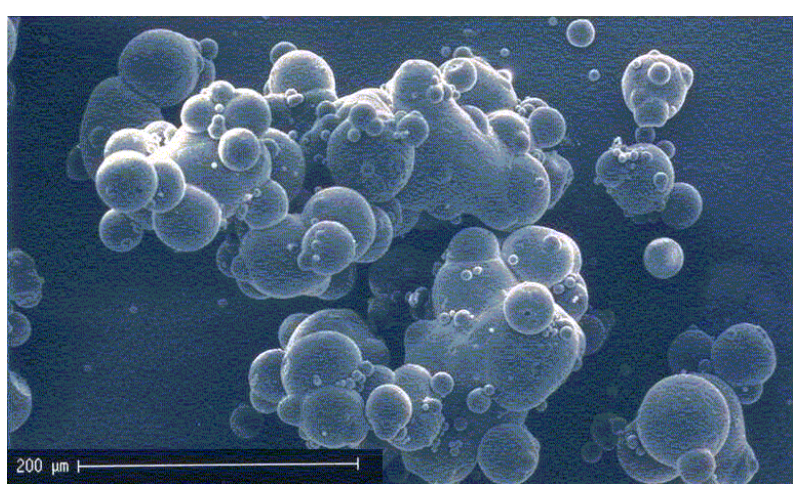

Figure 1. SEM-photograph of spray dried and agglomerated powder. Copyright 2004 from Verdurmen et al. [26]. Reproduced by permission of Taylor \& Francis, Inc., http:// www.taylorandfrancis.com 


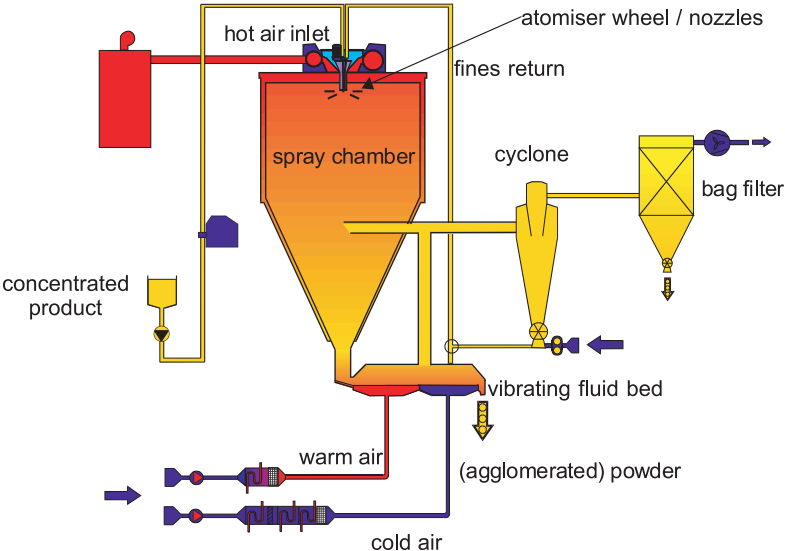

Figure 2. An industrial 2-stage spray dryer with fines return (courtesy of Anhydro A/S). coordinated by NIZO food research, entitled EDECAD (Efficient DEsign and Control of Agglomeration in spray Drying machines, www.edecad.com). The EDECAD project aimed at developing an industrially validated computer model, using computational fluid dynamics (CFD) technology, to predict agglomeration processes in spray drying machines.

This article intends to give an overview of the state-of-the-art. Further details can be found in the extensive article by Verdurmen et al. [26].

\section{SPRAY DRYING EQUIPMENT AND SPRAY DRYING MODELING}

Spray drying equipment for simultaneous drying and agglomeration is widely used in industry, for example in the production of milk products $[1,5,6,17,18,21]$.

Figure 2 schematically shows an example of an industrial spray dryer for the production of agglomerated powder. In the spray chamber the incoming product is atomized by rotary wheel atomizers or pressure nozzles and dried by the hot air introduced at the top. The powder particles leave the spray dryer at the bottom into the fluid bed, where further drying takes place. Most of the air leaves the spray chamber through the air outlet. Powder particles in the outlet air (small dry particles) are separated by a cyclone and can be reintroduced into the spray chamber (fines return) or into the fluid bed to enhance the agglomeration process.

Predictive computer models are helpful tools to maximize the production capacity of available installations, to minimize fouling of equipment and to reduce energy consumption. These models also reduce the number of costly and time-consuming production trials needed for the development of new products or processes. By Verdurmen et al. [25] an overview has been given how different modeling approaches can be applied to spray drying equipment. Currently, CFD is regarded as one of the best approaches to simulate spray drying processes in detail [10-12, 15, 23, 26, 29]. The airflow field, the local temperature (see Fig. 3 as an example) and the local humidity (see Fig. 4 as an example) inside the spray dryer can be computed by using CFD techniques, taking into account the coupling for mass, momentum and energy. The difference from standard (e.g. diesel sprays used in the automotive industry) spray calculations mainly concerns the drying part: stickiness primarily depends on the drying state of the outer layer of the particles. Additional submodels for moisture diffusion inside the particles [23] and for the relation between the drying state and stickiness [20] are 


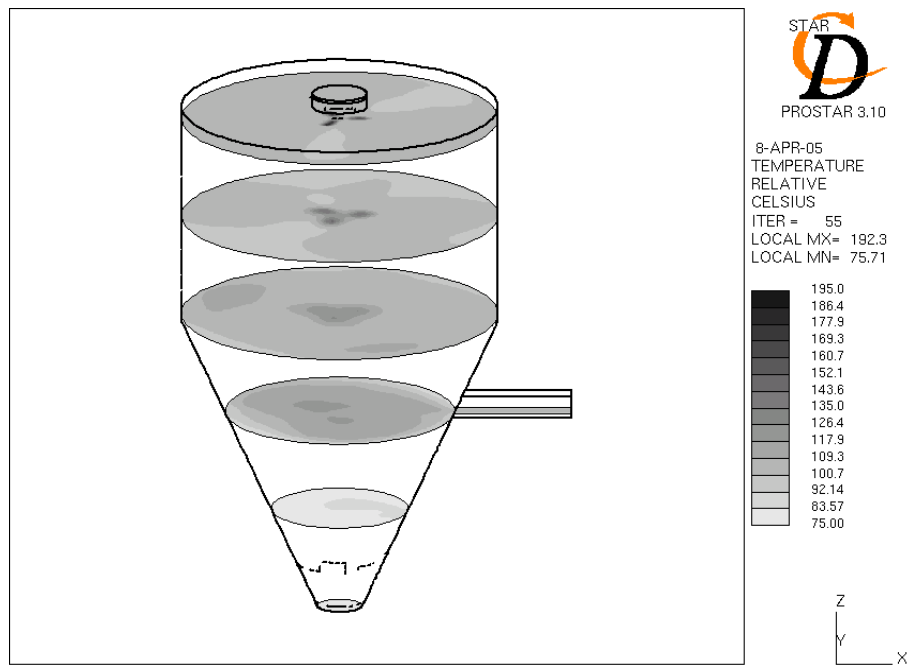

Figure 3. Simulation of temperature profiles $\left({ }^{\circ} \mathrm{C}\right)$.

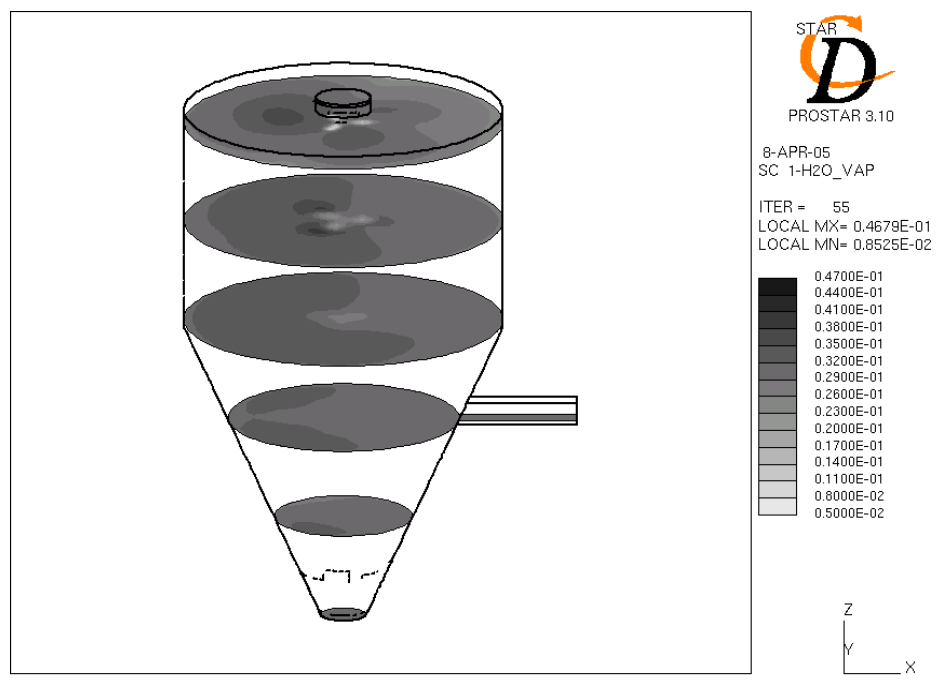

Figure 4. Simulation of an air humidity profile $\left(\mathrm{kg} \cdot \mathrm{m}^{-3}\right)$.

therefore required to be able to compute the drying and fouling behavior of spray drying systems.
To enhance the accessibility of CFD knowledge, the CD adapco Group (London, UK) and NIZO food research have 
cooperated to develop an Expert System for predicting the drying and fouling behavior of spray dryers: es-spraydry. An easy-to-use interface guides the user through defining the spray drying system, defining the product characteristics, setting up the processing conditions, mesh generation, running the calculations and post-processing the results. The es-spraydry tool can be used to design spray dryers, to check whether a specific dryer is suitable for a specific product or to investigate the effect of changes in processing conditions on the drying and fouling behavior of dryers [27].

\section{THE EDECAD APPROACH}

Some powder properties (e.g. insolubility) can be related to the moisture content and the temperature-time history of the particles [24]. For these properties the modeling techniques described above can be used. The majority of relevant powder quality properties, however, are related to the degree of agglomeration.

The aim of the EDECAD project has been to develop an industrially validated CFD model, a so called Design Tool, to predict agglomeration processes in spray drying machines. The project has focused on agglomeration that takes place at the upper part of the spray chamber, i.e. between sprays and between sprays and fines return. The modeling technique used is an extension of the Euler-Lagrange model for the drying and fouling behavior of spray dryers described above. New experimental methods and computer modeling techniques have been developed, such as:

- advanced measurement techniques (e.g. phase-doppler-anemometry) to determine the initial spray conditions of large capacity hollow cone pressure nozzles at relevant industrial conditions (e.g. atomization pressures of 200-220 bar and volume flows of 450-620 $\mathrm{L} \cdot \mathrm{h}^{-1}$ ) and fluids $[13,26]$;

- experimental techniques for the determination of the diffusion coefficient (to be used in the drying model) of industrial fluids using an acoustic levitator [26, 30, 31];
- novel experimental data on interacting sprays, to be used for validation of interdroplet collision and coalescence models $[2,14,26]$;

- stochastic and direct simulation Monte Carlo collision and coalescence model approaches implemented in CFD codes [3, 14, 22, 26];

- a newly developed agglomeration model enabling prediction of particle interaction in inhomogeneous and changing dispersed phase $[3,26]$;

- implementation of the glass transition concept in the agglomeration model [26], which is described in more detail below.

The initial spray conditions were measured and the sub-models for drying, collision and agglomeration were developed and validated by the academic partners in the project $[2-4,13,14]$. For a detailed description of the CFD model and its submodels and pilot-plant validation work carried out by the industrial partners we refer to Verdurmen et al. [26].

One of the key-issues in the EDECAD Design Tool is the use of a combined stochastic collision [22] and agglomeration model to predict the collision probability and impact details [3]. When a collision occurs, the drying state of the particles and the impact details determine whether the particles rebound, coalesce or agglomerate. Agglomeration occurs when particles are sticky. For many food products stickiness is strongly related to glass transition [20]. The particle composition and the moisture content of the outer layer determine the glass transition temperature $T_{g}$ and thereby the stickiness of the particle, which influences the agglomeration process. For skim milk solids for example, the stickiness and caking zone is positioned at about $10{ }^{\circ} \mathrm{C}$ or higher above the $\mathrm{T}_{\mathrm{g}}$ measured by DSC [ 9 , 20]. In the EDECAD project this is also confirmed by determining $\mathrm{T}_{\mathrm{g}}$ following the procedure described by Vuataz [28] and by determining the sticky point temperature as a function of water content using a static method, which is based on observing a change in structure at a given temperature and relative humidity content in a controlled air cabinet. The relation between the sticky 


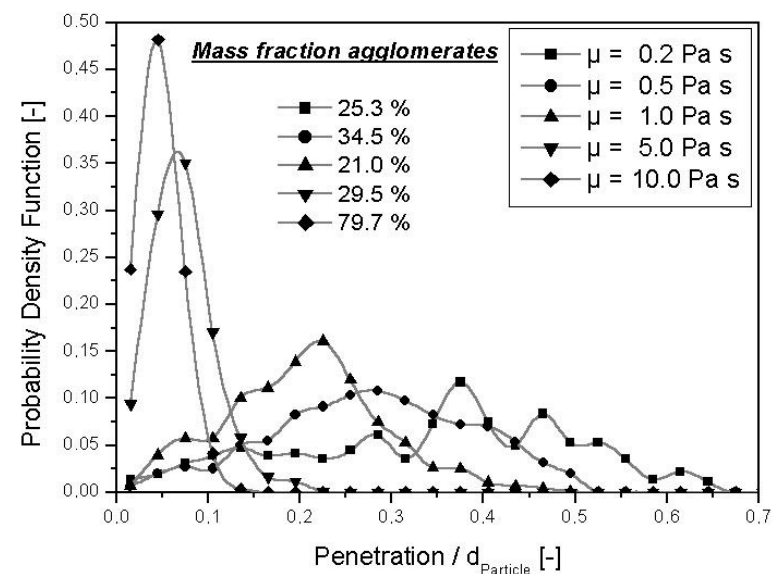

Figure 5. Test case results of the agglomeration model. Copyright 2004 from Verdurmen et al. [26] Reproduced by permission of Taylor \& Francis, Inc., http:// www.taylorandfrancis.com point temperature and water content is used in the agglomeration submodel.

\section{RESULTS}

Figure 5 shows the result of a theoretical test case calculation in a cubic geometry, initially containing a binary mixture of dry and viscous primary particles (e.g. fines and drying droplets). This theoretical test case illustrates the impact of viscosity (while drying) on the agglomeration model. The probability density function (normalized number of particles) of the relative penetration depth is shown for various viscosities. The penetration depth is the physical distance that two particles penetrate into each other after a collision. A low penetration depth is associated to agglomeration instead of coalescence. There is a significant influence of viscosity on agglomeration and the structure of agglomerates. With increasing viscosity the mass fraction of agglomerates (mass of agglomerates relative to mass of all particles in this simulation) increases, as given in the label of Figure 5. Moreover, penetration depths are reduced and the agglomerate size distribution becomes narrower, resulting in a larger, more homogeneous agglomerate population with improved pow- der properties. For further details see Verdurmen et al. [26].

Figure 6 shows a typical simulation result for the particle trajectories in the pilot plant dryer which was also used for the validation trials. The size of the particles shown in Figure 6 is a measure for the particle diameter. The results clearly show that the smaller particles (fines) leave the dryer through the air outlet, whereas the majority of the larger particles leave the dryer through the bottom of the dryer.

Figure 7 shows the initial particle size distribution at the nozzle and the computed size distribution at the bottom of the dryer corresponding to the calculation shown in Figure 6. Two cases have been simulated: without and with fines return. An increase in the particle size of the powder is observed when using a fines return configuration. This is in correspondence with experimental observations. In Table I the experimental and simulated average particle sizes are compared. It can be concluded that the simulations are giving results in the correct order of magnitude. On the other hand, there is still a need for further optimization. Special attention is to be paid on the correct prediction of viscosity during the drying process as this is an essential parameter for the agglomeration model. 


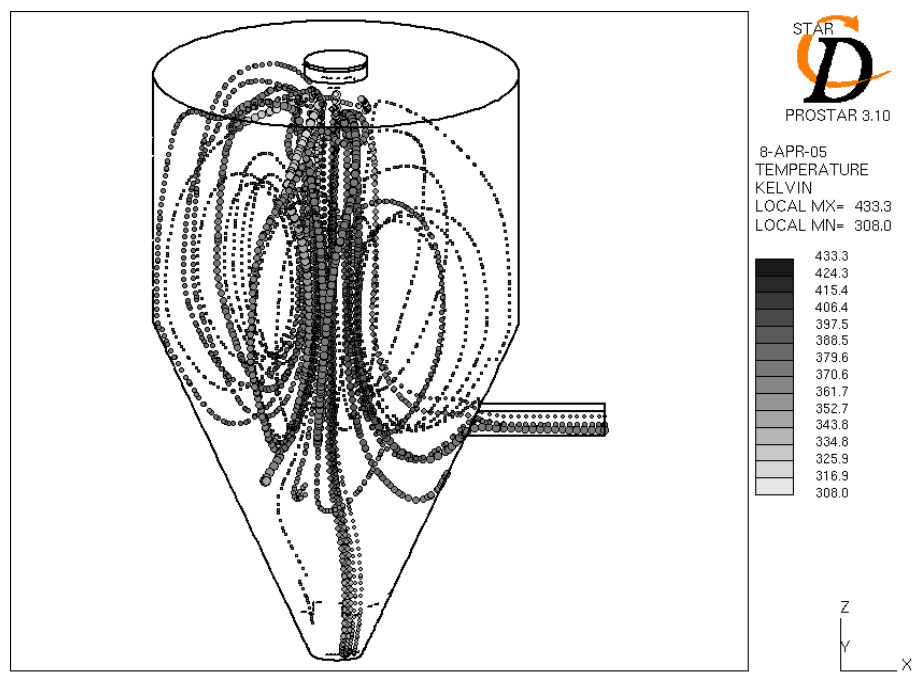

Figure 6. Simulated particle trajectories (the shown size is a measure of the particle diameter and the colours represent the particle temperature in K).

Table I. Comparison of powder particle size distributions of simulations and validating spray drying trials.

\begin{tabular}{lccc}
\hline & Simulations & $\begin{array}{c}\text { Measured directly } \\
\text { at dryer }\end{array}$ & $\begin{array}{c}\text { Measured after } \\
\text { transportation }\end{array}$ \\
\hline $\begin{array}{l}\text { without fines return average diameter } \\
\mathrm{d}(\mathrm{v}, 0.5) \text { in } \mu \mathrm{m}\end{array}$ & 95 & 103 & 92 \\
$\begin{array}{l}\text { without fines return } \\
\text { span [-]* } \\
\text { with fines return average diameter }\end{array}$ & 1.02 & 2.7 & 2.0 \\
$\mathrm{~d}(\mathrm{v}, 0.5)$ in $\mu \mathrm{m}$ \\
$\begin{array}{l}\text { with fines return } \\
\text { span [-]* }\end{array}$
\end{tabular}

* relative span is defined as $(\mathrm{d}(\mathrm{v}, 0.9)-\mathrm{d}(\mathrm{v}, 0.1)) / \mathrm{d}(\mathrm{v}, 0.5)$.

\section{CONCLUSION}

Predictive computer models have proven to be effective in reducing processing costs and improving product quality in the food industry. These models also reduce the number of costly and time-consuming pro- duction trials needed for the development of new products or processes. The development of models for the food industry is an ongoing process. By choosing an approach as used in the EDECAD project, agglomeration in spray dryers can now also be simulated. The resulting Design Tool establishes 


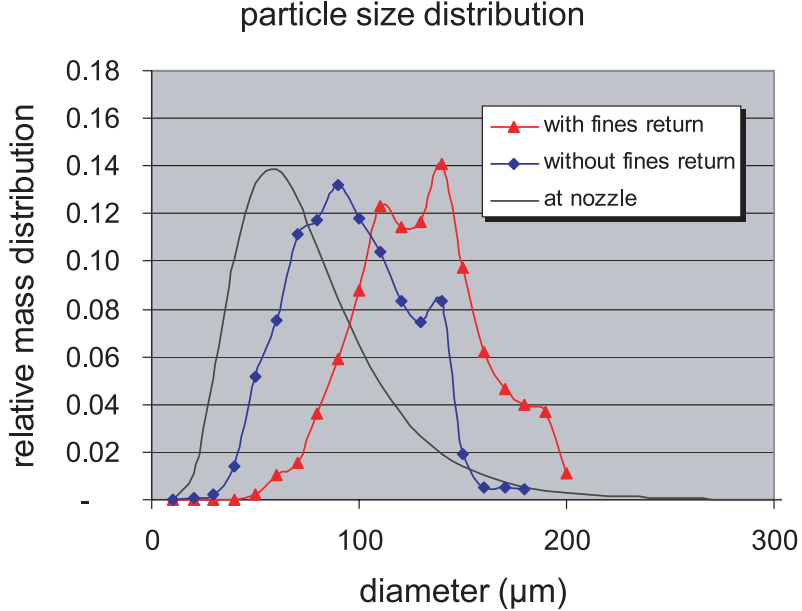

Figure 7. Particle size distribution at the nozzle (measured) and at the bottom of the dryer (simulated). relations between process parameters, degree of agglomeration (e.g. particle size distribution, porosity) and final powder properties. This can be used by the industry for improved design and optimisation of spray drying and agglomeration equipment, to improve the quality of products and to increase the productivity of such equipment.

Acknowledgements: This work is sponsored by the European Commission in the frame of the EC Fifth Framework Programme within the research programme "Competitive and Sustainable Growth" (contract G1RD-CT-2000-00340, http://www.edecad.com). The authors would like to thank the other project partners Armor Protéines, Royal Numico, Anhydro A/S, University of Manchester, Bremen University and TU Darmstadt for their participation and for supplying the products studied.

\section{REFERENCES}

[1] Bergquist D.H., Lorimor G.D., Wildy T.E., Mechanism and method for agglomerating food powders, Patent US 5130156, 1991.

[2] Blei S., Sommerfeld M., Lagrangian modelling of agglomeration during spray drying processes, in: Proceedings of the 9th International Conference on Liquid Atomization and Spray Systems, 13-17 July 2003, Sorrento, Italy, paper no. 1604.
[3] Blei S., Sommerfeld M., Computation of agglomeration for non-uniform dispersed phase properties - an extended stochastic collision model, in: Proceedings of the 5th International Conference on Multiphase Flow, ICMF'04, Yokohama, Japan, 30 May-4 June 2004, paper no. 438.

[4] Blei S., Sommerfeld M., Investigation of droplet collisions of viscous process fluids by imaging techniques, in: Proceedings ILASS Europe 2004, 19th Annual Conference on Liquid Atomization and Spray Systems, 6-8 September 2004, Nottingham, United Kingdom.

[5] Boersen A.C., Friso W.M., Spray drying device and feet means for this spray drying device, Patent WO 03090893, 2003.

[6] Deis R.C., Spray drying - innovative use of and old process, Food Prod. Des. 7 (1997) $97-113$.

[7] Graham B.H., Recent advances in agglomeration during spray drying, Food Aust. 49 (1997) 184-185.

[8] Hansen P.S., Production of agglomerated fatfilled milk powder., J. Soc. Dairy Technol. 33 (1980) 9-23.

[9] Hennings C., Kockel T.K., Langrish T.A.G., New measurements of the sticky behaviour of skim milk powder, in: Kerkhof P.J.A.M., Coumans W.J., Mooiweer G.D. (Eds.), Proceedings of the 12th International Drying Symposium IDS2000, Noordwijkerhout, The Netherlands, 28-31 August 2000, Elsevier Science, Amsterdam, The Netherlands, 2000.

[10] Huang L., Kumar K., Mujumdar A.S., Use of computational fluid dynamics to evaluate 
alternative spray dryer chamber configurations, Drying Technol. 21 (2003) 385-412.

[11] Huang L., Kumar K., Mujumdar A.S., Simulation of a spray dryer fitted with a rotary disk atomizer using a three-dimensional computer fluid dynamic model., Drying Technol. 22 (2004) 1489-1515.

[12] Kievit G.K., Modelling quality in spray drying, Thesis Eindhoven University of Technology, The Netherlands, 1997.

[13] Menn P., Schulte G., Bauckhage K., Experimental investigation of high pressure spray drying nozzle performance at industrial operating conditions, in: Proceedings of the 9th International Conference on Liquid Atomization and Spray Systems, 13-17 July 2003, Sorrento, Italy, paper no. 1602.

[14] Nhumaio G.C.S., Watkins A.P., Yule A.J., Experiments and CFD predictions of two overlapping water sprays issued from airassist atomizers, in: Proceedings ILASS Europe 2004, 19th Annual Conference on Liquid Atomization and Spray Systems, 6-8 September 2004, Nottingham, United Kingdom.

[15] Oakley D.E., Spray dryer modelling in theory and practice, Drying Technol. 22 (2004) 1371-1402.

[16] Pietsch W., Readily engineer agglomerates with special properties from micro-and nanosized particles, Chem. Eng. Prog. 95 (1999) 67-81.

[17] Písecký J., Handbook of Milk Powder Manufacture, Niro A/S, Copenhagen, Denmark, 1997.

[18] Písecký J., Hansen S.P., Process for producing an agglomerated powdery milk product, Patent EP 0378 498, 1990.

[19] Retsina T., Agglomeration: a process to improve fine powder handling, Food Technol. Int. Eur. (1988) 37-39.

[20] Roos Y.H., Importance of glass transition and water activity to spray drying and stability of dairy powders, Lait 82 (2002), 475-484.

[21] Shilton N.C., Niranjan K., Fluidization and its applications to food processing, Food Struct. 12 (1993) (2) 199-215.
[22] Sommerfeld M., Validation of a stochastic Lagrangian modeling approach for inter-particle collisions in homogeneous isotropic turbulence, Int. J. Multiphase Flow 27 (2001) 1829-1858.

[23] Straatsma J., van Houwelingen G., Steenbergen A.E., de Jong P., Spray drying of food products: 1. Simulation model, J. Food Eng. 42 (1999) 67-72.

[24] Straatsma J., van Houwelingen G., Steenbergen A.E., de Jong P., Spray drying of food products: 2. Prediction of insolubility index, J. Food Eng. 42 (1999) 73-77.

[25] Verdurmen R.E.M., Straatsma J., Verschueren M., van Haren J.J., Smit F., Bargeman G., de Jong, P., Modelling spray drying processes for dairy products, Lait 82 (2002) 453-463.

[26] Verdurmen R.E.M., Menn P., Ritzert J., Blei S., Nhumaio G.C.S., Sonne Sørensen T., Gunsing M., Straatsma J., Verschueren M., Sibeijn M., Schulte G., Fritsching U., Bauckhage K., Tropea C., Sommerfeld M., Watkins A.P., Yule A.J., Schønfeldt H., Simulation of agglomeration in spray drying installations: the EDECAD project, Drying Technol. 22 (2004) 1403-1461.

[27] Verschueren M., Verdurmen R.E.M., Gunsing M., Straatsma J., Blei S., Sommerfeld M., Spray drying in the food industry, CD adapco Dynamics 22 (2004) 31-34.

[28] Vuataz G., The phase diagram of milk: a new tool for optimising the drying process, Lait 82 (2002) 485-500.

[29] Xia B., Sun D.-W., Application of computational fluid dynamics (CFD) in the food industry: a review, Comput. Electron. Agric. 24 (2002) 5-24.

[30] Yarin A.L., Pfaffenlehner M., Tropea C., On the acoustic levitation of droplets, J. Fluid Mech. 356 (1998) 65-91.

[31] Yarin A.L., Brenn G., Kastner O., Rensink D., Tropea C., Evaporation of acoustically levitated droplets, J. Fluid Mech. 399 (1999) 151-204. 